\title{
Effects of propofol on myocardial ischemia-reperfusion injury in rats with type-2 diabetes mellitus
}

\author{
YING WANG $^{1}$, XIURU QI ${ }^{1}$, CHUNLIANG WANG $^{1}$, DANNING ZHAO ${ }^{1}$, \\ HONGJIE WANG $^{1}$ and JIANXIN ZHANG ${ }^{2}$ \\ ${ }^{1}$ Department of Anesthesiology, Affiliated Hospital of Hebei University, Baoding, Hebei 071000; \\ ${ }^{2}$ Department of Pharmacology, Hebei Academy of Medical Sciences, Shijiazhuang, Hebei 050021, P.R. China
}

Received September 2, 2016; Accepted October 21, 2016

DOI: $10.3892 /$ br.2016.805

\begin{abstract}
The current study aimed to examine the effects of propofol on myocardial ischemia-reperfusion injury (MIRI) in rats with type-2 diabetes mellitus (T2DM) and to assess the role of inflammatory mediators. Fifty healthy male adult Sprague-Dawley rats were randomly divided into the sham, ischemia-reperfusion (IR), IR plus low, middle and high-dose (6, 12 and $24 \mathrm{mg} / \mathrm{kg} / \mathrm{h}$, intravenous) propofol groups. The rats of all the groups were fed a high-sugar and high-fat diet for 8 weeks and streptozotocin ( $30 \mathrm{mg} / \mathrm{kg}$, intraperitoneally) was used to establish the T2DM model. Apart from the sham group rats, MIRI was induced by ligating the left anterior descending coronary artery for $30 \mathrm{~min}$, followed by reperfusion for $2 \mathrm{~h}$. Heart rate (HR), left ventricular systolic pressure (LVSP), and the rate of left ventricular pressure increase in early systole $\left( \pm d p / d t_{\max }\right)$ were recorded. Levels of cardiac troponin $\mathrm{T}$ (cTnT), nitric oxide (NO), endothelin-1 (ET-1), interleukin (IL)-1 $\beta$, IL-6, and tumor necrosis factor (TNF)- $\alpha$ were also measured. Myocardial lesions were observed under light microscopy and scanning electron microscopy. Compared with levels prior to arterial occlusion, $\mathrm{HR}$, LVSP, and $\pm \mathrm{dp} / \mathrm{dt}_{\max }$ were significantly reduced $(\mathrm{P}<0.05)$ following occlusion for $30 \mathrm{~min}$ and reperfusion for $2 \mathrm{~h}$. The administration of propofol ameliorated the cardiac function of rats as reflected by the increase in HR, LVSP and $\pm \mathrm{dp} / \mathrm{dt}_{\max }$. In addition, the administration of propofol increased the serum NO concentration, and reduced ET-1 and cTnT levels, as well as levels of inflammatory mediators including IL-1 $\beta$, IL- 6 and TNF- $\alpha$. Thus, propofol exerts protective effects against MIRI in T2DM rats by increasing NO and reducing ET-1 and the inflammatory mediators.
\end{abstract}

Correspondence to: Dr Hongjie Wang, Department of Anesthesiology, Affiliated Hospital of Hebei University, 212 Yuhua Road, Baoding, Hebei 071000, P.R. China

E-mail: hongjiew68@163.com

Key words: propofol, type-2 diabetes mellitus, myocardial ischemia-reperfusion injury, interleukin-1 $\beta$, interleukin-6, tumor necrosis factor- $\alpha$, cardiac troponin $\mathrm{T}$

\section{Introduction}

The incidence of type-2 diabetes mellitus (T2DM) is on the increase worldwide (1). The number of people succumbing to coronary heart disease is greatest in Europe, America, and urban areas of China. The number of T2DM patients succumbing to coronary heart disease is 2- to 4-fold that of non-T2DM patients (2). Previous findings have shown that the release of inflammatory mediators is closely associated with T2DM and myocardial ischemia-reperfusion injury (MIRI) (3-5). Inflammatory mediators may increase MIRI in patients with type-2 diabetes (6).

As a widely used intravenous anesthetic, propofol to some extent (7) protects the heart against IRI and reduces the expression of inflammatory mediators (8-10). Nevertheless, the protective effects of propofol against MIRI in T2DM rats and the effect of inflammatory mediators have not been investigated. Therefore, the aim of the study was to evaluate the effects of propofol on MIRI in T2DM rats and to determine the role of inflammatory mediators.

\section{Materials and methods}

A total of 50 healthy male Sprague-Dawley rats (6-8 weeks, 200-220 g) were provided by the Experimental Animal Center of Hebei Province, Shijiazhuang, China [certificate no. SCXK (Ji) 2013-1-1003]. The experiment was approved and carried out in accordance with the guidelines of Hebei University. The experimental protocols were performed in adherence with the Institutional Animal Care and Use Committee of Hebei University (Baoding, China).

All the rats were fed a high-sugar and high-fat diet at $22^{\circ} \mathrm{C}$ and humidity of $50 \%$. The feeding was provided by the Experimental Animal Center of Hebei Province (Shijiazhuang, China). After a period of eight weeks, streptozotocin $30 \mathrm{mg} / \mathrm{kg}$ body weight (Solarbio, Beijing, China) was injected into the abdomen to establish the T2DM model. It has been detected that fasting glucose is $\geq 14 \mathrm{~mol} / \mathrm{l}$ for the preparation of a successful model.

The rats were randomly divided into five groups ( $n=10 /$ group): i) Sham-operated group (sham), ii) ischemia-reperfusion (IR) and iii-v) IR plus low, middle and high-dose propofol (IR+L, M, H Pro). MIRI was induced 
Table I. Hemodynamic indices of myocardial ischemia-reperfusion injury in rats with type-2 diabetes mellitus ( $\mathrm{n}=10$, means \pm SD).

\begin{tabular}{|c|c|c|c|c|}
\hline Variable & Group & Before ligation & $\begin{array}{l}\text { After } 30 \mathrm{~min} \\
\text { of ischemia }\end{array}$ & $\begin{array}{l}\text { After } 2 \mathrm{~h} \text { of } \\
\text { reperfusion }\end{array}$ \\
\hline \multirow[t]{5}{*}{ Heart rate } & Sham & $424 \pm 15$ & $433 \pm 27$ & $421 \pm 8$ \\
\hline & IR & $423 \pm 19$ & $384 \pm 18^{\mathrm{a}, \mathrm{d}}$ & $217 \pm 28^{\mathrm{a}, \mathrm{d}}$ \\
\hline & IR+low-dose propofol & $418 \pm 19$ & $401 \pm 38^{a, b, d}$ & $242 \pm 37^{\mathrm{a}, \mathrm{b}, \mathrm{d}}$ \\
\hline & IR + middle-dose propofol & $420 \pm 18$ & $411 \pm 10^{\mathrm{a}, \mathrm{c}, \mathrm{d}}$ & $262 \pm 39^{\mathrm{a}, \mathrm{c}, \mathrm{d}}$ \\
\hline & IR+high-dose propofol & $419 \pm 16$ & $398 \pm 45^{\mathrm{a}, \mathrm{b}, \mathrm{d}}$ & $245 \pm 26^{\mathrm{a}, \mathrm{d}, \mathrm{b}}$ \\
\hline \multirow{5}{*}{$\begin{array}{l}\text { LVSP } \\
(\mathrm{mmHg})\end{array}$} & Sham & $124 \pm 12$ & $120 \pm 9$ & $116 \pm 9$ \\
\hline & IR & $123 \pm 9$ & $98 \pm 6^{\mathrm{a}, \mathrm{d}}$ & $68 \pm 7^{\mathrm{a}, \mathrm{d}}$ \\
\hline & IR+low-dose propofol & $122 \pm 11$ & $106 \pm 4^{\mathrm{a}, \mathrm{b}, \mathrm{d}}$ & $78 \pm 5^{\mathrm{a}, \mathrm{b}, \mathrm{d}}$ \\
\hline & IR+middle-dose propofol & $123 \pm 10$ & $112 \pm 10^{\mathrm{a}, \mathrm{c}, \mathrm{d}}$ & $80 \pm 8^{\mathrm{a}, \mathrm{c}, \mathrm{d}}$ \\
\hline & IR+high-dose propofol & $121 \pm 15$ & $110 \pm 5^{\mathrm{a}, \mathrm{b}, \mathrm{d}}$ & $75 \pm 10^{\mathrm{a}, \mathrm{b}, \mathrm{d}}$ \\
\hline \multirow[t]{5}{*}{$+\mathrm{dp} / \mathrm{dt}_{\max }$} & Sham & $3409 \pm 177$ & $3384 \pm 141$ & $3453 \pm 180$ \\
\hline & IR & $3348 \pm 167$ & $2583 \pm 315^{\mathrm{a}, \mathrm{d}}$ & $2243 \pm 359^{\mathrm{a}, \mathrm{d}}$ \\
\hline & IR+low-dose propofol & $3385 \pm 246$ & $2735 \pm 436^{\mathrm{a}, \mathrm{b}, \mathrm{d}}$ & $2696 \pm 217^{\mathrm{a}, \mathrm{b}, \mathrm{d}}$ \\
\hline & IR+middle-dose propofol & $3392 \pm 321$ & $2881 \pm 356^{\mathrm{a}, \mathrm{c}, \mathrm{d}}$ & $2755 \pm 312^{\mathrm{a}, \mathrm{c}, \mathrm{d}}$ \\
\hline & IR+high-dose propofol & $3378 \pm 259$ & $2801 \pm 345^{\mathrm{a}, \mathrm{b}, \mathrm{d}}$ & $2522 \pm 215^{\mathrm{a}, \mathrm{b}, \mathrm{d}}$ \\
\hline \multirow[t]{5}{*}{$-\mathrm{dp} / \mathrm{dt}_{\max }$} & Sham & $3819 \pm 144$ & $3582 \pm 268$ & $3548 \pm 396$ \\
\hline & IR & $3883 \pm 93$ & $2620 \pm 186^{\mathrm{a}, \mathrm{d}}$ & $2232 \pm 427^{\mathrm{a}, \mathrm{d}}$ \\
\hline & IR+low-dose propofol & $3887 \pm 174$ & $2830 \pm 484^{\mathrm{a}, \mathrm{b}, \mathrm{d}}$ & $2781 \pm 430^{\mathrm{a}, \mathrm{b}, \mathrm{d}}$ \\
\hline & IR+midle-dose propofol & $3822 \pm 124$ & $2845 \pm 320^{\mathrm{a}, \mathrm{c}, \mathrm{d}}$ & $2788 \pm 562^{a, c, d}$ \\
\hline & IR+high-dose propofol & $3857 \pm 152$ & $2785 \pm 182^{\mathrm{a}, \mathrm{b}, \mathrm{d}}$ & $2635 \pm 352^{a, b, d}$ \\
\hline
\end{tabular}

Compared with sham group, ${ }^{\mathrm{a}} \mathrm{P}<0.05$; compared with IR group, ${ }^{\mathrm{b}} \mathrm{P}<0.05,{ }^{\mathrm{c}} \mathrm{P}<0.01$; compared with before, ${ }^{\mathrm{d}} \mathrm{P}<0.05$. IR, ischemia-reperfusion; $\mathrm{SD}$, standard deviation.

by ligating the left anterior descending coronary artery for $30 \mathrm{~min}$, followed by reperfusion for $2 \mathrm{~h}$. The rats in the sham group received an intravenous infusion of physiologic $(0.9 \%)$ saline $(3 \mathrm{mg} / \mathrm{kg} / \mathrm{h})$ for $10 \mathrm{~min}$ without ligation. In the IR group, the rats received an intravenous infusion of physiologic saline $(3 \mathrm{mg} / \mathrm{kg} / \mathrm{h})$ for $10 \mathrm{~min}$ before IR. In the IR+L, M, H Pro group rats, Pro (6, 12 and $24 \mathrm{mg} / \mathrm{kg} / \mathrm{h}$, intravenous) was respectively administered for $10 \mathrm{~min}$ before IR. The rats were sacrificed after IR in the treatment groups.

The rats were anesthetized, and a polyethylene Millar catheter was inserted into the right common carotid artery and then further advanced into the left ventricular chamber, after which the cannula was connected to a pressure transducer. The heart rate (HR), left ventricular systolic pressure (LVSP), and the rate of left ventricular pressure increase in early systole $\left( \pm \mathrm{dp} / \mathrm{dt}_{\max }\right)$ were recorded by an 8 -channel polygraph system (Powerlab 8s; ADInstruments, Castle Hill, New South Wales, Australia). The levels of cardiac troponin T (cTnT), nitric oxide (NO), endothelin-1 (ET-1), interleukin (IL)-1 $\beta$, IL-6, and tumor necrosis factor (TNF)- $\alpha$ were respectively measured using an enzyme-linked immunosorbent assay. Myocardial lesions were observed under light microscopy and scanning electron microscopy.

Statistical analysis. SPSS v16.0 (IBM, Armonk, NY, USA) was used for all the analyses. Hemodynamics were compared and analyzed within groups and between groups by multivariate analysis of variance. cTnT, NO, ET-1, IL-1 $\beta$, IL-6, and TNF- $\alpha$ levels were compared using one-way ANOVA. The $95 \%$ confidence interval was used for significance.

\section{Results}

Changes in cardiac function. The HR, LVSP and $\pm \mathrm{dp} / \mathrm{dt}_{\max }$ were significantly decreased after IR compared with those before ligation $(\mathrm{P}<0.05)$. No significant difference was observed in HR, LVSP and $\pm \mathrm{dp} / \mathrm{dt}_{\max }$ before ligation. Compared with that of the sham group, HR, LVSP and $\pm \mathrm{dp} / \mathrm{dt}_{\max }$ were significantly decreased in the IR group rats $(\mathrm{P}<0.05)$. Compared with those of the IR group, HR, LVSP and $\pm \mathrm{dp} / \mathrm{dt}_{\max }$ were significantly increased in the $\mathrm{IR}+\mathrm{L}$, M, H Pro group rats $(\mathrm{P}<0.05$; Table I).

Changes in NO, ET-1 and cTnT in the serum. Compared with those of the sham group, NO was reduced, and ET-1 and cTnT were significantly increased in the IR group rats $(\mathrm{P}<0.05)$. Compared with those of the IR group, NO was increased, and ET-1 and cTnT were significantly reduced in the IR+L, M, H Pro group rats $(\mathrm{P}<0.05$; Table II).

Changes in $I L-1 \beta, I L-6$ and TNF- $\alpha$ in the serum. Compared with those of the sham group, IL-1 $\beta$, IL- 6 and TNF- $\alpha$ were significantly increased in the IR group rats $(\mathrm{P}<0.05)$. Compared with those of the IR group, IL-1 $\beta$, IL- 6 , TNF- $\alpha$ 
Table II. Serum concentrations of NO, ET-1 and cTnT ( $\mu \mathrm{mol} / \mathrm{l})$ in the different groups $(n=10$, means \pm SD).

\begin{tabular}{lccc}
\hline Group & NO & ET-1 & cTnT \\
\hline Sham & $83 \pm 3.2$ & $3.90 \pm 0.25$ & $14.60 \pm 1.0$ \\
IR & $55 \pm 2.5^{\mathrm{a}}$ & $8.45 \pm 0.32^{\mathrm{a}}$ & $25.56 \pm 1.3^{\mathrm{a}}$ \\
$\begin{array}{l}\text { IR+low-dose } \\
\text { propofol }\end{array}$ & $72 \pm 3.8^{\mathrm{a}, \mathrm{b}}$ & $5.52 \pm 0.31^{\mathrm{a}, \mathrm{b}}$ & $18.89 \pm 2.1^{\mathrm{a}, \mathrm{b}}$ \\
$\begin{array}{l}\text { IR+middle } \\
\text { dose propofol }\end{array}$ & $81 \pm 3.2^{\mathrm{a}, \mathrm{c}}$ & $4.33 \pm 0.42^{\mathrm{a}, \mathrm{c}}$ & $17.12 \pm 0.9^{\mathrm{a}, \mathrm{c}}$ \\
$\begin{array}{l}\text { IR+high } \\
\text { dose propofol }\end{array}$ & $75 \pm 3.5^{\mathrm{a}, \mathrm{b}}$ & $5.32 \pm 0.38^{\mathrm{a}, \mathrm{b}}$ & $19.75 \pm 1.2^{\mathrm{a}, \mathrm{b}}$ \\
\hline
\end{tabular}

Compared with sham group, ${ }^{a} \mathrm{P}<0.05$; compared with IR group, ${ }^{\mathrm{b}} \mathrm{P}<0.05,{ }^{\mathrm{c}} \mathrm{P}<0.01$. NO, nitric oxide; ET-1, endothelin-1; cTnT, cardiac troponin $\mathrm{T}$; SD, standard deviation.
Table III. Serum concentrations of IL-1 $\beta$, IL-6, and TNF- $\alpha$ $(\mu \mathrm{mol} / \mathrm{l})$ in the different group $(\mathrm{n}=10$, means $\pm \mathrm{SD})$.

\begin{tabular}{llll}
\hline Group & IL-1 $\beta$ & IL-6 & TNF- $\alpha$ \\
\hline sham & $173.19 \pm 23$ & $177.38 \pm 15$ & $198.21 \pm 15$ \\
IR & $259.86 \pm 18^{\mathrm{a}}$ & $253.48 \pm 16^{\mathrm{a}}$ & $562.58 \pm 19^{\mathrm{a}}$ \\
$\begin{array}{l}\text { IR+low-dose } \\
\text { propofol }\end{array}$ & $238.68 \pm 18^{\mathrm{a}, \mathrm{b}}$ & $216.36 \pm 19^{\mathrm{a}, \mathrm{b}}$ & $385.15 \pm 20^{\mathrm{a}, \mathrm{b}}$ \\
$\begin{array}{l}\text { IR+middle } \\
\text { dose propofol }\end{array}$ & $194.20 \pm 20^{\mathrm{a}, \mathrm{c}}$ & $191.13 \pm 18^{\mathrm{a}, \mathrm{c}}$ & $334.59 \pm 21^{\mathrm{a}, \mathrm{c}}$ \\
$\begin{array}{l}\text { IR+high } \\
\text { dose propofol }\end{array}$ & $217.58 \pm 21^{\mathrm{a}, \mathrm{b}}$ & $215.23 \pm 18^{\mathrm{a}, \mathrm{b}}$ & $362.31 \pm 25^{\mathrm{a}, \mathrm{b}}$ \\
\hline
\end{tabular}

Compared with sham group, ${ }^{a} \mathrm{P}<0.05$; compared with IR group, ${ }^{\mathrm{b}} \mathrm{P}<0.05,{ }^{\mathrm{c}} \mathrm{P}<0.01$; IR, ischemia-reperfusion; TNF- $\alpha$, tumor necrosis factor- $\alpha$; IL, interleukin; SD, standard deviation.

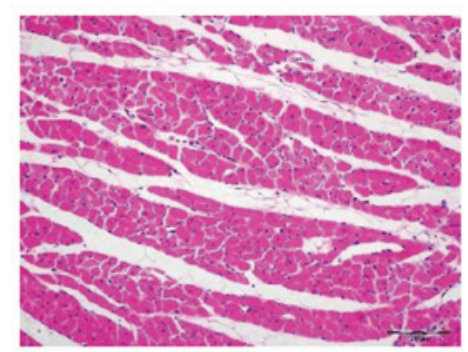

Sham

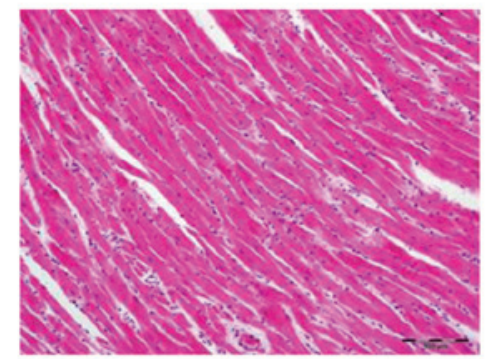

IR+middle-dose propofol

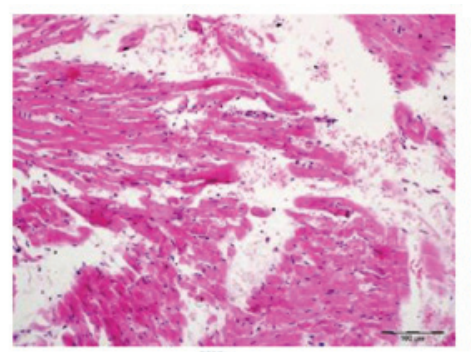

IR

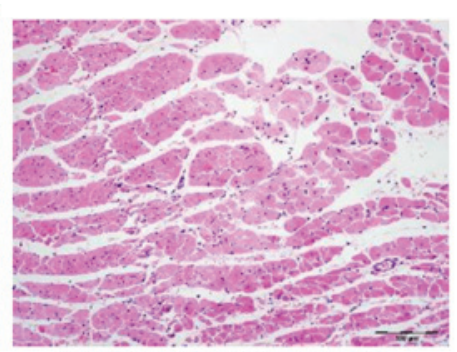

IR+low-dose propofol

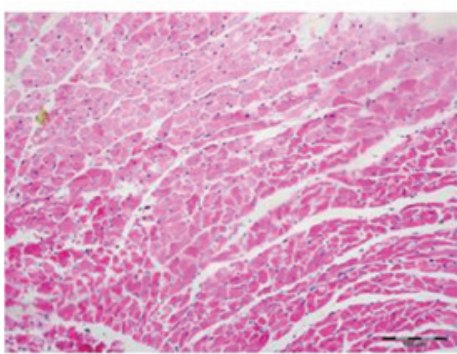

IR+high-dose propofol

Figure 1. Pathologic alterations in heart of rats with hematoxycylin and eosin staining (magnification, $\mathrm{x} 20$; scale bar, $100 \mu \mathrm{m}$ ). IR, ischemia-reperfusion.

were significantly reduced in the $\mathrm{IR}+\mathrm{L}, \mathrm{M}, \mathrm{H}$ Pro group rats $(\mathrm{P}<0.05$; Table III).

Morphologic changes under light microscopy. No myocardial fibrosis and normal nuclear morphology was uniformed in the sham group. Myocardial fibers and stromal necrosis, eosinophil-enhanced muscle cells, elongated wavy/fragmented myocardial fibrosis, with most nuclei showing fragmentation and degeneration were observed in the IR group. Eosinophil-enhanced myocardial fibrosis was evident, along with elongated wavy/fragmented cardiac muscle fibres arranged in an orderly manner, with most nuclei showing pyknosis and fragmentation in the IR+low-dose propofol and IR+high-dose propofol groups. Eosinophil-enhanced myocardial fibrosis, elongation of myocardial fibers and hyperchromatic nuclei were observed in the IR+middle-dose propofol group (Fig. 1).
Ultrastrucral changes under electron microscopy. The integrity of the membrane and cristae of mitochondria and myocardial fibrosis were clearly visible, and the integrity of inner and outer nuclear membranes of nuclei was retained in the sham group rats. In the IR group, swelling of mitochondria, rupture and disappearance of mitochondrial membranes, dissolution of edema between mitochondria, absence of chromatin, disappearance of the outer nuclear envelope, disappearance of some inner and outer nuclear envelopes, and perinuclear edemawere observed. Mitochondrial degeneration and necrosis of myocardial fibers, indistinct sarcomeres, and an absence of muscle-fiber structure were revealed. In the IR+low-dose propofol and IR+high-dose propofol groups, mitochondrial edema, mitochondrial films, and the partial disappearance of mitochondria were observed. Additionally, high-density chromatin, partial disappearance of the outer layer of nuclear films (but not of nuclear film 


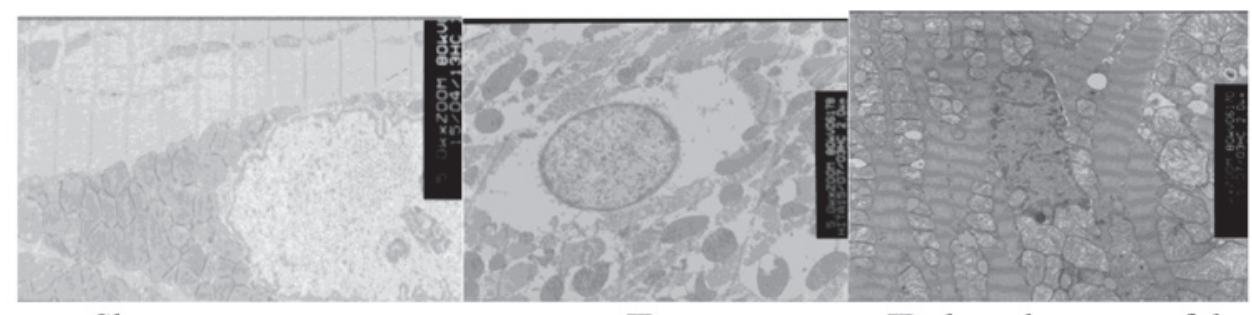

Sham

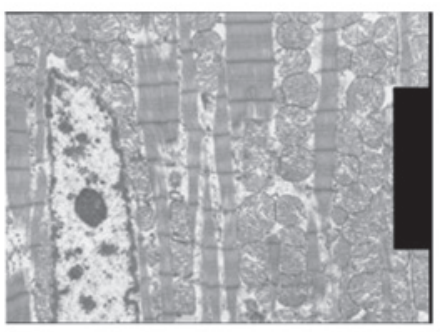

IR+middle-dose propofol
IR

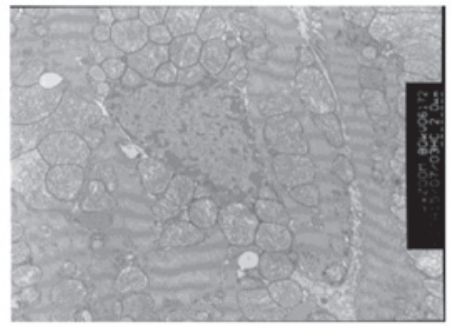

IR+high-dose propofol

IR+low-dose propofol

Figure 2. Ultrastructural changes in the heart of rats with electron microscopy (magnification, x3,500). IR, ischemia-reperfusion.

within layers), mild edema between muscle fibers, mild damage to myocardial fibers, and comparatively neat muscle arrangement, were observed. In the IR+middle-dose propofol group, some mitochondrial edema was present, along with chromatin-dense masses but no obvious perinuclear edema or lighter myocardial fibrosis was observed, and sarcomeres were aligned (Fig. 2).

\section{Discussion}

In the present study, our results demonstrated that propofol ameliorated cardiac function, increased serum NO and decreased ET-1 and inflammatory mediators against MIRI in T2DM rats.

In 1966, Jennings et al first suggested the concept of IR injury which involves destruction of the tissue structure and metabolic disorders (11). For instance, in clinical heart surgery, infarction after coronary artery ligation is observed after MIRI. Furthermore, type-2 diabetes is one of the most common endocrine metabolic diseases, and myocardial injury was increased in type- 2 diabetes resulting in diabetic cardiovascular disease having the highest morbidity and mortality $(12,13)$. In the present experiment, we used the traditional preparation methods of a type- 2 diabetes model. Fasting glucose $\geq 14 \mathrm{~mol} / \mathrm{l}$ was considered as the successful model. HR, LVSP, and $\pm \mathrm{dp} / \mathrm{dt}_{\max }$ were significantly reduced after IR was compared with those before ligation. These results indicate that the MIRI model was successfully established.

Evidence indicates that the intravenous anesthesic propofol may inhibit lipid peroxidation, improve mitochondrial function (14), protect the myocardium and reduce MIRI in rats (15). Furthermore, it improves the function of vascular endothelial cells and promotes the expression of anti-apoptotic proteins, thus reducing MIRI in T2DM. Several clinical and biochemical indices may be used for the diagnosis of myocardial injury. cTnT is considered to be the 'gold standard' for the diagnosis of myocardial injury. In the present study, propofol decreased the cTnT concentration in serum and ameliorated cardiac function, as reflected by an increase in $\mathrm{HR}$, LVSP and $\pm \mathrm{dp} / \mathrm{dt}_{\max }$. In addition, the myocardial damage degree was significantly decreased after the administration of propofol. Therefore, propofol has myocardial protection for type-2 diabetes rat myocardial IR.

Since 1980, Furchgott and Zawadzki identified the endothelial diastolic factor (EDRF) (16). In 1988, Yanagisiawa et al (17) first extracted ET from swine aortic endothelial cultures and found that vascular endothelial cells between blood circulation and vascular smooth muscle cells play an important role in regulating cardiovascular activity. EDRF is NO and it has a strong function of diastolic blood vessels and inhibits vascular smooth muscle cell proliferation and thrombosis (18). At the time of myocardial ischemia, the change of NO level was controversial. Previous findings showed that NO release was increased in coronary artery myocardial ischemia (19-21). By contrast, other authors found that NO release was decreased $(22,23)$. The function of endothelium plays an important role in maintaining stability and normal blood flow dynamics. The key factor of its function is the NO. Vascular endothelial often constantly release NO into the vascular smooth muscle cells so as to maintain vascular tension in a moderate degree of relaxation state (24). NO exerts anti-inflammatory effects by inhibiting the neutrophil adhesion to endothelial cells and decreasing the release of inflammatory factors. An appropriate amount of NO could protect cardiomyocytes, reduce damage, inhibit intimal hyperplasia and ameliorate the heart function following IR injury. As an important regulator of cardiovascular function, ET plays a significant role in maintaining vascular tension and cardiovascular system steady state (25). Endothelial cells stimulate the synthesis and release of ET-1. ET-1 is responsible for endothelial dysfunction and inflammation and contributes to atherosclerotic plaque formation (26). ET-1 induces the left ventricular afterload increase and participates in the fibrotic process of the myocardium $(27,28)$. Adrenaline, 
thromboxane, angiotensin, insulin, inflammatory factors and hypoxia stimulated the synthesis of ET-1, and the inhibitors of ET-1 synthesis included NO, PGI2, atrial natriuretic peptide and heparin. This experiment showed that propofol could increase the NO level and decrease the serum ET-1 concentration, thus exerting the cardioprotective effects on MIRI in T2DM rats.

Studies have shown that T2DM and MIRI are associated with inflammatory mediators (6-8). The inflammatory factors potentially cause the myocardial damage in T2DM patients. Thus, inhibition of the release of inflammatory cytokines is an important strategy to protect heart against myocardial damage in T2DM patients. As an important inflammatory cytokine, TNF- $\alpha$ is produced mainly by the activation of monocytes/macrophages, and participates in certain autoimmune diseases (29-33). Thus, it could stimulate the NO synthase (i-NOS) to synthesize and release a large number of NO. NO and the ultra oxygen anion reaction occurs rapidly, and subsequently the oxidation ability stronger light free radicals was generated. Which could make the cell membrane lipid peroxide and the tissue damage was aggravating (34). IL-1 $\beta$ is produced mainly by macrophages and it was found that systemic reactions resulted from injection and secretion of large amounts of IL-1 (35). IL-6 is mainly generated by macrophages, T-cells, B-cells and other cell types. IL- 6 contributed to the cachexia induced by TNF- $\alpha$ and IL-1, and promotes glucocorticoid synthesis. IL-6 has an important role against infection as reflected by increasing the effects of other cytokines and regulating the immune response, acute-phase response and hematopoiesis. Inflammation factor occupies an important position on MIRI. Inflammation caused by myocardial ischemia and hypoxia promotes the release of large quantities of ILs from monocytes and macrophages. As neutrophil chemotactic factors with high specificity, the ILs cause adhesion and gathering of numerous white blood cells (the obstacles against mini-circulation), an increase of active oxygen and damage myocardial cells (36-38). Inflammatory factors resulted in neutrophils releasing cytotoxicity, aggravating the inflammatory reaction, blocking blood capillaries, vascular active substances, thereby leading to acute tissue damage (38). The results of the present study have shown that propofol decreased the expression of inflammatory cytokines, such as IL-1 $\beta$, IL-6, TNF- $\alpha$ in serum.

In conclusion, our data provide strong supportive evidence that propofol has protective effects on MIRI in T2DM rats as reflected by ameliorating cardiac function, the increasing serum NO and decreasing serum ET-1, IL-1 $\beta$, IL- 6 and TNF- $\alpha$.

\section{References}

1. Shaw JE, Sicree RA and Zimmet PZ: Global estimates of the prevalence of diabetes for 2010 and 2030. Diabetes Res Clin Pract 87: 4-14, 2010.

2. de Mattos Matheus AS, Righeti Monteiro Tannus L, Roberta Arnoldi Cobas R, Sousa Palma CC, Negrato CA and de Brito Gomes M: Impact of diabetes on cardiovascular disease: An update (Review). Int J Hypertens 2013: 653789, 2013.

3. Sun L and Kanwar YS: Relevance of TNF- $\alpha$ in the context of other inflammatory cytokines in the progression of diabetic nephropathy. Kidney Int 88: 662-665, 2015.

4. Hashmi S and Al-Salam S: Acute myocardial infarction and myocardial ischemia-reperfusion injury: A comparison. Int J Clin Exp Pathol 8: 8786-8796, 2015.

5. Halladin NL: Oxidative and inflammatory biomarkers of ischemia and reperfusion injuries. Dan Med J 62: B5054, 2015.
6. Marfella R, Di Filippo C, Portoghese M, Siniscalchi M, Martis S, Ferraraccio F, Guastafierro S, Nicoletti G, Barbieri M, Coppola A, et al: The ubiquitin-proteasome system contributes to the inflammatory injury in ischemic diabetic myocardium: The role of glycemic control. Cardiovasc Pathol 18: 332-345, 2009.

7. Yao X, Li Y, Tao M, Wang S, Zhang L, Lin J, Xia Z and Liu HM Effects of glucose concentration on propofol cardioprotection against myocardial ischemia reperfusion injury in isolated rat hearts. J Diabetes Res 2015: 592028, 2015.

8. Liu F, Chen MR, Liu J, Zou Y, Wang TY, Zuo YX and Wang TH: Propofol administration improves neurological function associated with inhibition of pro-inflammatory cytokines in adult rats after traumatic brain injury. Neuropeptides 58: 1-6, 2016.

9. Markovic-Bozic J, Karpe B, Potocnik I, Jerin A, Vranic A and Novak-Jankovic V: Effect of propofol and sevoflurane on the inflammatory response of patients undergoing craniotomy. BMC Anesthesiol 16: 18, 2016.

10. Samir A, Gandreti N, Madhere M, Khan A, Brown M and Loomba V: Anti-inflammatory effects of propofol during cardiopulmonary bypass: A pilot study. Ann Card Anaesth 18: 495-501, 2015.

11. Jennings MA,BrockLG and Florey L: A comparison of connective tissue lining aortic grafts with extravascular connective tissue. Proc R Soc Lond B Biol Sci 165: 206-223, 1966.

12. Cha SA, Yun JS, Lim TS, Hwang S, Yim EJ, Song KH, Yoo KD, Park YM, Ahn YB and Ko SH: Severe hypoglycemia and cardiovascular or all-cause mortality in patients with type 2 diabetes. Diabetes Metab J 40: 202-210, 2016.

13. Lee E, Oh HJ, Park JT, Han SH, Ryu DR, Kang SW and Yoo TH: The incidence of cardiovascular events is comparable between normoalbuminuric and albuminuric diabetic patients with chronic kidney disease. Medicine (Baltimore) 95: e3175, 2016.

14. Shao H, Li J, Zhou Y, Ge Z, Fan J, Shao Z and Zeng Y: Dose-dependent protective effect of propofol against mitochondrial dysfunction in ischaemic/reperfused rat heart: Role of cardiolipin. Br J Pharmacol 153: 1641-1649, 2008.

15. Noh HS, Shin IW, Ha JH, Hah Y-S, Baek SM and Kim DR: Propofol protects the autophagic cell death induced by the ischemia/reperfusion injury in rats. Mol Cells 30: 455-460, 2010.

16. FurchgottRF and Zawadzki JV: The obligatory role of endothelial cells in the relaxation of arterial smooth muscle by acetylcholine. Nature 288: 373-376, 1980

17. Yanagisawa M, Kurihara H, Kimura S, Tomobe Y, Kobayashi M, Mitsui Y, Yazaki Y, Goto K and Masaki T: A novel potent vasoconstrictor peptide produced by vascular endothelial cells. Nature 332: 411-415, 1988.

18. Moncada S, Palmer RM and Higgs EA: Nitric oxide: Physiology, pathophysiology, and pharmacology. Pharmacol Rev 43: 109-142, 1991.

19. Kilbourn RG, Jubran A, Gross SS, Griffith OW, Levi R, Adams J and Lodato RF: Reversal of endotoxin-mediated shock by NG-methyl-L-arginine, an inhibitor of nitric oxide synthesis. Biochem Biophys Res Commun 172: 1132-1138, 1990.

20. Wildhirt SM, Dudek RR, Suzuki H, Pinto V, Narayan KS and Bing RJ: Immunohistochemistry in the identification of nitric oxide synthase isoenzymes in myocardial infarction. Cardiovasc Res 29: 526-531, 1995.

21. Hoshida S, Yamashita N, Igarashi J, Nishida M, Hori M, Kamada T, Kuzuya $\mathrm{T}$ and Tada M: Nitric oxide synthase protects the heart against ischemia-reperfusion injury in rabbits. J Pharmacol Exp Ther 274: 413-418, 1995.

22. Yao SK, Akhtar S, Scott-Burden T, Ober JC, Golino P, Buja LM, Casscells W and Willerson JT: Endogenous and exogenous nitric oxide protect against intracoronary thrombosis and reocclusion after thrombolysis. Circulation 92: 1005-1010, 1995.

23. Zweier JL, Wang P and Kuppusamy P: Direct measurement of nitric oxide generation in the ischemic heart using electron paramagnetic resonance spectroscopy. J Biol Chem 270: 304-307, 1995.

24. Node K, Kitakaze M, Kosaka H, Komamura K, Minamino T, Inoue $\mathrm{M}$, Tada M, Hori $\mathrm{M}$ and Kamada $\mathrm{T}$ : Increased release of NO during ischemia reduces myocardial contractility and improves metabolic dysfunction. Circulation 93: 356-364, 1996.

25. Mayyas F, Al-Jarrah M,Ibrahim K, Mfady D and Van Wagoner DR The significance of circulating endothelin-1 as a predictor of coronary artery disease status and clinical outcomes following coronary artery catheterization. Cardiovasc Pathol 24: 19-25, 2015. 
26. Lewicki L, Siebert J, Marek-Trzonkowska N, Masiewicz E, Kolinski T, Reiwer-Gostomska M, Targonski R and Trzonkowski P: Elevated serum tryptase and endothelin in patients with ST segment elevation myocardial infarction: Preliminary report. Mediators Inflamm 2015: 395173, 2015.

27. Kolettis TM, Barton M, Langleben D and Matsumura Y: Endothelin in coronary artery disease and myocardial infarction. Cardiol Rev 21: 249-256, 2013.

28. Chen J, Chen MH, Guo YL, Zhu CG, Xu RX, Dong Q and Li JJ: Plasma big endothelin-1 level and the severity of new-onset stable coronary artery disease. J Atheroscler Thromb 22: $126-135,2015$

29. Carswell EA, Old LJ, Kassel RL, Green S, Fiore N and Williamson B: An endotoxin-induced serum factor that causes necrosis of tumors. Proc Natl Acad Sci USA 72: 3666-3670, 1975.

30. Tang X, Marciano DL, Leeman SE and Amar S: LPS induces the interaction of a transcription factor, LPS-induced TNF-alpha factor, and STAT6(B) with effects on multiple cytokines. Proc Natl Acad Sci USA 102: 5132-5137, 2005.

31. Kleine TO, Zwerenz P, Zöfel P and Shiratori K: New and old diagnostic markers of meningitis in cerebrospinal fluid (CSF). Brain Res Bull 61: 287-297, 2003.

32. Li X, Huang Q, Ong CN, Yang XF and Shen HM: Chrysin sensitizes tumor necrosis factor-alpha-induced apoptosis in human tumor cells via suppression of nuclear factor-kappaB. Cancer Lett 293: 109-116, 2010.
33. Singh U, Kumar A, Sinha R, Manral S, Arora S, Ram S, Mishra RK, Gupta P, Bansal SK, Prasad AK, et al: Calreticulin transacetylase catalyzed modification of the TNF-alpha mediated pathway in the human peripheral blood mononuclear cells by polyphenolic acetates. Chem Biol Interact 185: 263-70, 2010.

34. Suzuki Y, Deitch EA, Mishima S, Lu Q and Xu D: Inducible nitric oxide synthase gene knockout mice have increased resistance to gut injury and bacterial translocation after an intestinal ischemia-reperfusion injury. Crit Care Med 28: 3692-3696, 2000.

35. Oleszycka E, Moran HB, Tynan GA, Hearnden CH, Coutts G, Campbell M, Allan SM, Scott CJ and Lavelle EC: IL-1 $\alpha$ and inflammasome-independent IL- $1 \beta$ promote neutrophil infiltration following alum vaccination. FEBS J 283: 9-24, 2016.

36. Ma J, Qiao Z and Xu B: Effects of ischemic preconditioning on myocardium Caspase-3, SOCS-1, SOCS-3, TNF- $\alpha$ and IL-6 mRNA expression levels in myocardium IR rats. Mol Biol Rep 40: 5741-5748, 2013.

37. Ishihara Y, Sekine M, Nakazawa M and Shimamoto N: Suppression of myocardial ischemia-reperfusion injury by inhibitors of cytochrome P450 in rats. Eur J Pharmacol 611: 64-71, 2009.

38. Hadi NR, Al-Amran F, Yousif M and Zamil ST: Antiapoptotic effect of simvastatin ameliorates myocardial ischemia/reperfusion injury. ISRN Pharmacol 2013: 815094, 2013. 